\title{
OS ENCAPUSLADORES E SEU PAPEL NA TESSITURA TEXTUAL/DISCURSIVA
}

\begin{abstract}
Margareth Andrade Morais
Doutora em Letras (Letras Vernáculas) pela Universidade Federal do Rio de Janeiro (UFRJ)

margareth.morais@ifrj.edu.br
\end{abstract}

\section{RESUMO}

O objetivo deste artigo é discutir o uso textual discursivo de anáforas encapsuladoras, à luz de aspectos sociodiscursivos e sociointeracionais, ampliando, assim, a compreensão do papel desse elemento. Traçamos um panorama teórico dos estudos de referenciação, considerado como um processo sociocognitivo de construção de sentidos, seguindo os estudos atuais de Linguística de Texto, conforme já apontaram Mondada e Dubois (2003), Cavalcante (2011), Santos e Cavalcante (2014), dentre outros autores. Com base nesses autores, serão analisadas notícias esportivas mostrando como os encapsuladores atuam na construção do texto, marcando pontos de vista e construindo sentidos, para além da classificação tradicional desse processo de referenciação.

Palavras-chave: encapsuladores; construção de sentidos; Linguística de Texto.

\section{ABSTRACT}

The objective of this article is to discuss the discursive textual use of encapsulating anaphors in the light of sociodiscursive and sociointerational aspects, thus broadening the understanding of the role of this element. We present a theoretical panorama of the reference studies, considered as a sociocognitive process of sense construction, following the current studies of Text Linguistics, as already pointed out by Mondada and Dubois (2003), Cavalcante (2011), Santos e Cavalcante (2014), among other authors. Based on these authors, sports news will be analyzed, showing how the anaphora encapsulation act in the construction of the text, marking points of view and constructing meanings, beyond the traditional classification of this process.

Keywords: anaphora encapsulation; meaning construction; Text Linguistics. 


\section{Introdução}

O encapsulador é um processo referencial que merece destaque, pois se apresenta como uma escolha capaz de sumarizar informações presentes no cotexto e, ao mesmo tempo, transformá-las em novo objeto de discurso. Esse processo de referenciação foi definido como "um recurso coesivo pelo qual um sintagma nominal funciona como síntese de uma porção do cotexto que pode possuir extensão variada", conforme descreve Conte (2003, p. 178).

Com o avanço da Linguística de Texto, os estudos sobre referenciação, cada vez mais, entendem que os encapsulamentos atuam na construção dos referentes, organizando e sumarizando opiniões, como apontam Conte (2003), Cavalcante (2011), Borreguero (2006), entre outros. Além disso, esses autores também destacam como tal recurso pode contribuir para a orientação argumentativa dos textos, tendo em vista uma argumentatividade inerente a todos os textos.

Desse modo, o presente trabalho pretende discutir essa característica dos encapsuladores em textos que não tenham, a princípio, um viés argumentativo, isto é, textos que não pertençam à tipologia argumentativa, como as notícias esportivas.

O objetivo deste artigo, portanto, é colaborar para o debate sobre o fenômeno do encapsulamento, trazendo à tona aspectos sociointeracionais e sociodiscursivos. Serão discutidos exemplos presentes em notícias esportivas referentes a jogos da Copa do Mundo de 2014, publicadas nos jornais O Globo e Lance!, e, para a análise dos dados, será a utilizada a proposta de Morais (2017). Pretende-se mostrar como os encapsuladores atuam na construção do texto, marcando posicionamentos ideológicos e construindo sentidos que vão além da classificação tradicional. 


\section{Os encapsuladores em foco}

Além de apresentarem um importante papel coesivo e organizar os tópicos dentro do discurso, os encapsulamentos podem, a partir de informações já mencionadas no texto, implementar um objeto quase novo para discurso, remetendo a informações não explicitadas no cotexto, como pressupostos, subentendidos e outros conteúdos presentes na memória discursiva dos participantes da interação. Desse modo, uma de suas principais propriedades reside no fato de que seu referente não é claramente delimitado no texto. Esse referente deve ser reconstruído pelo interlocutor, ou seja, a anáfora encapsuladora não retoma, pontualmente, nenhum objeto de discurso, e sim se vincula a informações contidas em porções de texto presentes no cotexto.

Por sua capacidade de retomar um referente não expresso, mas difundido no contexto, expresso de modo esparso, pode apresentar um alto teor argumentativo. Isso ocorre porque, no ato da nomeação, podem ser empregados rótulos com grande carga avaliativa. Dessa forma, a anáfora encapsuladora pode exercer uma função argumentativa decisiva para uma tomada de ponto de vista do texto, estabelecendo uma nova cadeia referencial a partir desse momento.

Pecorari (2014, p. 22) chama atenção para a propriedade dos encapsuladores de carregar valores pressupostos que podem tanto trazer para os textos julgamentos, como também podem corroborar para enfatizar valores sociais da esfera do senso comum. Segundo o autor, que analisou notícias de jornais italianos, os encapsuladores podem cumprir o papel, dentro da linguagem do jornal, de compartilhar ideias que fazem parte do senso comum de determinada comunidade. Pecorari defende que o encapsulador tem 
um efeito persuasivo sobre o leitor que, por estar em uma posição cooperativa, acaba sendo levado a aceitar o caminho argumentativo proposto pelo encapsulador. Por outro lado, o autor também aponta que alguns encapsulamentos, mesmo aqueles com nomes avaliativos, nem sempre carregam valores persuasivos, podendo confirmar avaliações e julgamentos compartilhados e aceitos entre os interlocutores e, muitas vezes, as notícias se valem desse recurso para veicular uma aparente neutralidade.

O levantamento dessas características e propriedades demonstra que as anáforas encapsuladoras se comportam de maneira híbrida. Segundo Borreguero (2006), as anáforas encapsuladoras apresentam um correferente no texto, não apresentando um novo referente no discurso. Para a autora, as anáforas encapsuladoras são anáforas diretas, pois, ainda que não se possa indicar um único item como antecedente, é possível recuperá-lo dentro do texto. De acordo com a autora, os encapsuladores não fazem referência a um único elemento linguístico, mas a uma parte do texto que pode conter uma oração ou até mesmo um parágrafo.

Conte (2003) já afirmava que as anáforas encapsuladoras misturam características das anáforas diretas e indiretas. Santos e Cavalcante (2014) também afirmam que tais anáforas parecem comportar-se como um item intermediário entre anáforas diretas e indiretas, uma vez que, ainda que se apoiem em informações dadas, podem introduzir um novo referente. Quanto à relação de correferencialidade, entretanto, é possível notar um grau de correferencialidade entre a parte do texto sintetizada e o encapsulador, o que o aproximaria de uma anáfora direta. Nesse sentido, para Borreguero (2006), prevalecerá a questão da correferencialidade, e o encapsulador será definido como uma anáfora direta. Para a autora, há uma relação anafórica entre o sintagma e os elementos textuais 
antecedentes, que contribuem para homologar a significação dos objetos de discurso, como se fosse uma continuidade de um discurso já existente.

Cavalcante, Custódio Filho e Brito (2014) também compartilham dessa abordagem sobre os encapsuladores. Os autores argumentam que o referente fica representado na mente dos interlocutores e isso é um indício de que esse processo pode ser tratado como um subtipo de anáfora correferencial, ainda que seja um pouco fora do padrão de uma anáfora direta. Tais autores ainda defendem que, se entendemos o referente como uma entidade representada sociocognitivamente e abstraída do contexto de enunciação, é plausível admitir que, ao ser nomeado, o referente já existia no texto. Nas palavras dos autores,

[...] mesmo sem ser citado antes da expressão encapsuladora, o referente fica representado na mente dos interlocutores, e é esta a razão pela qual preferimos tratá-lo como um subtipo de anáfora correferencial, ainda que diferente ou fora dos padrões (CUSTÓDIO FILHO; BRITO, 2014, p. 80).

Para eles, a questão da retomada a um referente já introduzido no discurso e presente na mente dos interlocutores leva à correferencialidade, que se sobrepõe às demais características do encapsulador, sendo o fator preponderante para a classificação desse processo.

Essas nuances no comportamento do encapsulador levam a corroborar o que apontam Santos e Cavalcante (2014) para quem as anáforas encapsuladoras devem ser entendidas em um continuum entre as anáforas diretas e indiretas. Desse modo, como alguns encapsuladores apresentam correferencialidade de maneira mais clara, ao passo 
que outros demonstram um comportamento mais prototípico de uma anáfora indireta, assume-se, nesse trabalho, que não se está diante de fenômenos isolados, mas que se cruzam e se misturam, tendo em vista uma perspectiva sociocognitiva e interacional. Portanto, entende-se aqui que os encapsuladores, em relação à correferencialidade, situam-se em uma zona intermediária.

\section{Os encapsuladores nas notícias esportivas}

O objetivo das notícias esportivas é sintetizar jogos de futebol, cujo resultado geralmente já é conhecido pelo leitor, que busca mais informações e um toque de curiosidade sobre o jogo em questão. Atualmente, as notícias esportivas não ficam restritas à publicação de resultados dos jogos e campeonatos, ampliando a possibilidade de cobertura para temas como a política dos clubes, situação financeira, entre outros. Em relação à linguagem, Barbeiro e Rangel (2006) destacam que o texto esportivo, de modo geral, detém maior liberdade no tratamento da matéria. Segundo os autores, na editoria de esportes, o humor e a leveza são perceptíveis, e o vocabulário, muitas vezes, consagra expressões populares, sendo mais criativo.

A seguir, estão destacados alguns dos exemplos mais recorrentes de encapsulamentos nas notícias esportivas referentes aos jogos da Copa do Mundo de 2014 (MORAIS, 2017).

(1) $O$ resultado, porém, não significa o adeus da outra campeã do mundo, a Inglaterra. Tudo dependerá do jogo de hoje entre Itália e Costa Rica, no Recife. Um empate elimina os ingleses. Assim como uma vitória costarriquenha. Isso porque, com esse resultado, os ingleses não conseguirão alcançar a pontuação de pelo menos dois rivais do Grupo D. (GOMES, Guilherme. $O$ jogo dos sonhos de Suárez. Jornal Lance!. Rio de Janeiro, 20 de junho de 2014, p. 13) 
O encapsulador "o resultado" faz a articulação entre os parágrafos anteriores do texto e aponta para o novo tema que surge na progressão do texto, funcionando como um tópico discursivo (cf. JUBRAN, 1992). O pronome "isso" retoma e sintetiza a explicação sobre a possibilidade de classificação das equipes citadas. Já a expressão "esse resultado" retoma a situação que envolve a possibilidade de vitória costarriquenha, o que desclassificaria a equipe inglesa. Chama atenção, ainda, o uso do pronome demonstrativo "esse", que situa o leitor dentro do texto para que ele recupere o referente dessa expressão de modo eficiente, mostrando que a troca da classe gramatical do determinante nos sintagmas nominais cumpre um propósito dentro do texto.

No exemplo abaixo (2), também se verifica o uso do pronome demonstrativo como encapsulador:

(2) A Argentina venceu a Holanda porque foi muito mais competente nos pênaltis, após 0 a 0 no tempo normal e na prorrogação, mas não foi só isso. Os Hermanos fizeram muito do que o time de Luiz Felipe Scolari, que deveria jogar no Maracanã domingo, não o fez na terça no Mineirão. (PORTO, Marcio. Corrida para o tri. Jornal Lance! Rio de Janeiro, 10 de julho, p. 10).

Para desfazer a imagem de um jogo sem emoções - conteúdo pressuposto por ter sido um jogo sem gols -, em que os lances principais só saíram na prorrogação, há a relação discursivo-argumentativa de oposição marcada pela oração "mas não foi só isso", que procura descartar essa possível leitura. O uso do advérbio "só" com o pronome "isso" reforça a tese de que o jogo foi interessante. Isto é, ainda que os gols tenham acontecido somente na disputa de pênaltis, não quer dizer que o jogo tenha sido sem emoção.

É importante destacar também que o pronome "isso" não só sintetiza a porção anterior do texto, como também cria uma expectativa para algo que ainda vai ser dito, ou 
seja, também aponta "para frente" no texto. Ao dizer que "não foi só isso", o jornalista gera no leitor uma curiosidade sobre o que se seguiu na partida. Por isso, pode-se dizer que esse mecanismo realiza um duplo movimento no texto, de continuidade e progressão, retomando porções já ditas e antecipando que mais informações serão ditas. Tal característica é pouco discutida nos estudos sobre encapsulamento - principalmente quando o encapsulador é o pronome "isso". Muitas vezes, destaca-se o papel de organizador desse processo de referenciação tendo em vista somente a sua propriedade de retomar partes já ditas.

Dentro dos exemplos que contribuem para a organização textual, o encapsulamento prospectivo sublinhado abaixo inicia um novo tópico no discurso e reitera a orientação argumentativa do texto que trata da superação do time holandês:

(3) A inversão de papéis começou antes de a bola rolar. Ao contrário da final de 2010, era a Holanda a usar azul. Ao cair na área aos 25 minutos, o brasileiro naturalizado espanhol Diego Costa já percebera a dificuldade para se livrar dos zagueiros e das vaias. Xabi Alonso bateu o pênalti e fez o único gol da Espanha, um suspiro antes do afogamento total. (AMATO, Gian. Laranja amarga. Jornal $O$ Globo. Rio de Janeiro, 14 de junho de 2014, p. 8)

Tendo em vista o parágrafo anterior da notícia, esse parágrafo, com o encapsulador "a inversão de papéis", retoma o conteúdo anterior e a relação estabelecida pelas anáforas diretas "papel de coadjuvante" e "protagonista Espanha", além de marcações dêiticas de tempo presentes no parágrafo anterior, que estabelecem um "antes e depois" no discurso, coincidindo com o tópico instaurado pelo encapsulador "a inversão de papéis".

Assim, além de resumir o conteúdo anterior, esse encapsulamento inicia um novo tópico discursivo: a vitória da Holanda sobre a Espanha. De acordo com Burdiles e Parodi (2016), os encapsuladores prospectivos e retrospectivos relacionam-se à organização e 
hierarquização das informações dentro do texto, o que comprova o papel fundamental desses mecanismos na compreensão de textos, que podem tanto retomar informações já mencionadas como antecipar novos conteúdos.

Koch e Elias (2016, p. 95) afirmam que os encapsuladores podem funcionar como um importante recurso para "marcar o parágrafo do ponto de vista cognitivo". É exatamente o que acontece nesse exemplo, pois as informações textuais precedentes conduzem a uma imagem mental dos objetos de discurso Holanda e Espanha, que será oposta no próximo parágrafo. Essa "virada" dos objetos de discurso é marcada pelo encapsulador "a inversão de papéis", indicando o assunto a ser desenvolvido, definindo cognitivamente essa unidade construtiva do texto.

Em (4), o encapsulador foi utilizado como um recurso que antecipa lances da partida:

(4) Dispostos a se defender até o fim, os americanos levaram sorte no chute de Hazard, aos 42, que acertou a rede pelo lado de fora. A melhor chance do jogo, no entanto, veio já nos acréscimos, quando Wondolowski recebeu livre na área, mas concluiu por cima do gol de Courtois, sob olhar incrédulo do ex-artilheiro Klinsmann. (BENJAMIM, Felipe. Bélgica bate Estados Unidos. Jornal Globo. Rio de Janeiro, 2 de julho, caderno de esportes)

O encapsulamento "melhor chance do jogo" descreve o que, para o jornalista, representou o lance mais interessante da etapa normal de jogo: a jogada norteamericana. Em seguida, o operador argumentativo disjuntivo "no entanto" traz para o texto uma orientação argumentativa de que, apesar da superioridade belga ao longo da partida, a melhor jogada foi norte-americana. Tal conteúdo também é reforçado pelo vocábulo "melhor". Para Conte (2003, p.186) a anáfora encapsuladora "funciona simultaneamente como um recurso coesivo e como um princípio organizador, e pode ser 
um poderoso meio de manipulação do leitor", pois o fato de o produtor do texto rotular um conteúdo contribui para sua força argumentativa, como acontece no exemplo destacado.

De modo semelhante ao anterior, o próximo exemplo também apresenta um encapsulamento que rotula e avalia um determinado lance do jogo, que o jornalista julga ter sido “o mais dramático”:

(5) Aos 38, o lance mais dramático da primeira etapa: Mostefa aparou um rebote de fora da área, a bola desviou em Boateng e, com Neuer completamente batido, passou à direita do gol. Na seqüência, Schweinsteiger chutou de fora da área, o goleiro M'Bolhi bateu roupa e em seguida defendeu a pancada à queima-roupa de Götze. (ILHA, Fávio. Batalha no sul. Jornal Globo. Rio de Janeiro, 1 de julho de 2014, p. 7)

Esse encapsulamento promove um efeito de suspense em relação a um lance quase no final do primeiro tempo de jogo: "o lance mais dramático da primeira etapa". Tal recurso apresenta e qualifica todo o conteúdo do parágrafo que encabeça, pois o que se segue no restante do parágrafo é a descrição detalhada do que seria a jogada mais importante do primeiro tempo da partida.

Convém destacar a noção de tópico discursivo e como tal noção está diretamente ligada à referenciação. Dentre todos os processos, o encapsulamento exerce um papel importante de continuidade ou de progressão tópica. Como observou Pinheiro (2003), os encapsuladores, além dos papéis citados, podem realçar um dado conteúdo, reforçando ou esclarecendo o ponto de vista do enunciador.

Em (6), também se observou o uso do encapsulador prospectivo na notícia que trata do jogo entre México e Brasil: 
(6) Com Oscar bem abaixo da estreia e Neymar muito bem marcado, a equipe brasileira teve dificuldades para furar o forte bloqueio mexicano. No primeiro tempo, as melhores chances do Brasil foram numa cabeçada de Neymar aos 25 e numa conclusão de Paulinho, após lindo passe de Thiago Silva com o peito, já nos acréscimos. Em ambas Ochoa brilhou. (FONSECA, Maurício. México segura o Brasil. Jornal $O$ Globo. 18 de junho, p. 3).

O sintagma "as melhores chances do Brasil", que aponta para frente no texto, refere-se à cabeçada de Neymar e à finalização de Paulinho. Esse encapsulamento, além de resumir os principais lances da primeira etapa de jogo, evidencia o julgamento desses lances por meio do adjetivo "melhores". A escolha desse termo permite ao jornalista caracterizar as ações dos jogadores, pois carrega um juízo de valor. Dentro do contexto da notícia, "melhores" apresenta um valor depreciativo, pois as jogadas foram fracas e, mesmo assim, constituíram os melhores lances da equipe brasileira. Essa operação prova que existiu uma interpretação por parte do jornalista, que acaba por guiar as inferências realizadas pelo leitor.

Em (7), o nome "voo" encapsula a jogada holandesa protagonizada pelo jogador Holandês Van Persie:

(7) $O$ voo de Van Persie sobre a área iniciou a decolagem da Holanda. Após receber passe certeiro de Blind, o camisa 9 praticamente ficou no ar, com o corpo na horizontal, antes de cabecear e encobrir Casillas, aos 44 minutos. (AMATO, Gian. Laranja amarga. Jornal $O$ Globo. Rio de Janeiro, 14 de junho de 2014, p. 8)

O substantivo "voo" - uma metáfora comum no futebol que designa uma jogada aérea - funciona como encapsulador prospectivo, que antecipa o lance do gol de cabeça do jogador holandês. Tal encapsulamento contribui ainda para outras relações no texto, servindo de âncora para a anáfora indireta "decolagem holandesa", que marca o início da goleada holandesa, já que, após o gol do jogador Van Persie, a Holanda passou a dominar 
a Espanha. Essas amarras anafóricas reforçam a orientação argumentativa da notícia ao enfatizar a superioridade holandesa.

Os últimos exemplos tratam de encapsulamentos também metafóricos que rotulam o jogo inteiro. O primeiro, retirado da notícia do jornal Lance! sobre a partida entre Argélia e Alemanha:

(8) Foi absolutamente dramático. As Raposas do Deserto resistiram como puderam. Mas essa guerra a Alemanha ganhou, por 2 a 1, mesmo que a sua divisão panzer - Özil, Schweinsteiger e Müller - ainda não tenha repetido a blitzkrieg da estreia sobre Portugal. (ASSAF, Roberto. Não foi fácil. Jornal Lance! Rio de Janeiro, 1 de julho de 2014, p. 20)

O encapsulador prospectivo "guerra" carrega uma forte carga axiológica, caracterizando todo o jogo, e serve de âncora para as relações que vão se estabelecer dentro do texto, evidenciadas por meio de outras palavras, que revelam este projeto de dizer: o jogo como uma guerra. No mesmo parágrafo, há o emprego de outro encapsulamento: "divisão panzer", que compara o uso da artilharia pesada do exército alemão, com tanques e veículos blindados, aos jogadores que compõem o ataque da seleção alemã. A "divisão panzer" era responsável pelo sucesso do exército alemão, assim como esse trio de jogadores também compõe a principal estratégia para vitória.

O próximo exemplo apresenta um caso diferente de encapsulamento. O título "Chucrute na Bahia", por meio da anáfora encapsuladora "chucrute" engaja o leitor no texto já com a perspectiva do sucesso alemão, já que, na Bahia, prevaleceu “o prato típico alemão". Nesse sentido, as informações presentes no subtítulo, bem como a própria introdução do referente "Alemanha", contribuem para que o co-enunciador perfaça a trilha de sentido que leva à vitória alemã, juntamente com o acervo cultural compartilhado entre os interlocutores. 
(9) Chucrute na Bahia

Sempre favorita ao título, Alemanha não toma conhecimento de Portugal e marca quatro gols logo em sua estreia. E ainda tem o artilheiro do Mundial até agora: Thomas Müller, autor de três ontem. (AMATO, Gian. Chucrute na Bahia. Jornal Globo. Rio de Janeiro, 17 de junho de 2014, p. 7)

No entanto, cabe destacar que o nome "chucrute", ao contrário dos demais analisados anteriormente, não é um nome abstrato, contrariando os exemplos mais discutidos de encapsulamento. Tais exemplos, em geral, são compostos por nomes de significação mais ampla e que, por essa característica, estariam mais propensos a serem usados como encapsuladores. Conte (2003), por exemplo, afirma que os encapsulamentos são formados por nomes mais gerais ou nomes com carga avaliativa. No caso acima, pelo contrário, trata-se de um nome concreto que passa a abstrato, já que rotula, metaforicamente, a vitória alemã sobre Portugal. Não há, no desenvolvimento da notícia, nenhuma menção à culinária alemã, ou seja, não há uma âncora ou pista a que pudéssemos associar o nome "chucrute", o que comprova que esse vocábulo é tomado, nesse texto, de modo abstrato.

Além disso, pensando no prato "chucrute", um repolho bem picado, por vezes considerado indigesto, poderíamos associar esse nome ao próprio resultado do jogo, que, para além da vitória da Alemanha, consistiu em uma goleada sobre Portugal, o que poderia sugerir, ainda, que esse título aponta para a expressividade da vitória alemã. Nos campeonatos nacionais, por exemplo, é comum os locutores e jornalistas esportivos empregarem o termo "chocolate" para se referirem a vitórias expressivas constituídas por placares amplos.

Esse substantivo encapsula informações que só podem ser processadas pelo leitor por meio de estruturas cognitivas. Assim, "Chucrute na Bahia", pode ser considerado não 
como uma menção ao prato, mas como uma metáfora para a vitória alemã na Bahia, local onde ocorreu a partida.

No próximo excerto, há um caso que se assemelha ao descrito anteriormente:

(10) O curioso é que a Espanha saiu na frente, gol de pênalti - de De Vrij em Diego Costa - aos 26 minutos, teve maior domínio e desperdiçou uma excelente oportunidade aos 42 , por capricho de David Silva, que tentou encobrir Cillessen. Não seria exagero dizer que essa foi o que se chama de bola do jogo, pois se entra talvez mudasse o rumo do duelo. Ah... e só tomou o empate aos 44, num peixinho de Van Persie. (ASSAF, Roberto. Um dia sem fúria. Jornal Lance! Rio de janeiro, 14 de julho de 2014, p. 14).

$\mathrm{Na}$ ação descrita pela frase "desperdiçou uma excelente oportunidade" há uma crítica contida no verbo desperdiçar, que aponta uma falha do jogador, reforçada pelo encapsulamento prospectivo "uma excelente oportunidade aos 42", em que o adjetivo excelente enfatiza essa crítica. Soma-se a essa interpretação a própria descrição do lance, dizendo-se que o atacante, David Silva, "por capricho", tentou encobrir o goleiro, o que indica que o jogador tentou uma jogada com menor probabilidade de acerto, porém esteticamente mais bonita, ou na linguagem do futebol, mais plástica.

O encapsulamento "bola do jogo" resume não só a oportunidade perdida, mas todo o contexto que cerca a partida, mostrando como poderia ter mudado o placar e garantido a vitória holandesa. Esse exemplo também se assemelha ao anterior, já que o substantivo concreto "bola" ganha um valor metafórico, deixando de se referir apenas à bola para mostrar uma jogada crucial para o desenrolar da partida e que poderia definir a participação da Holanda na final da Copa do Mundo.

Os dois últimos exemplos mostram como um substantivo concreto perde a sua concretude dentro do texto, de modo oposto ao que se espera de um elemento encapsulador, já que, quanto mais abstrato, maior a capacidade de abarcar porções 
maiores do cotexto. No entanto, como se defende nesse artigo, todas essas relações são homologadas no e pelo texto, o que comprova a importância de uma análise ampla do fenômeno, que considere aspectos sociodiscursivos e interacionais.

\section{Considerações finais}

Percebeu-se, nos exemplos analisados por Morais (2017), que os encapsuladores, se analisados em uma perspectiva sociocognitiva e interacional, observando suas especificidades em um gênero textual como a notícia esportiva, comportam-se de maneira bastante peculiar. Retomando Santos e Cavalcante (2014, p. 243), destaca-se que, em uma concepção de texto como processo, "precisamos analisar os exemplos observando esse processo sociocognitivo e interacional, complexo e abrangente".

As anáforas encapsuladoras mostraram-se uma estratégia fundamental para a condução da orientação argumentativa das notícias esportivas, evidenciando críticas e avaliações sobre jogadores e seleções, por exemplo, ou até mesmo foram utilizadas para construir um efeito de neutralidade nos textos.

Demonstrou-se, portanto, o que relembram Cabral e Santos (2016), ao afirmarem que o sujeito, tendo a língua como base, insere-se no enunciado e constrói com ele objetos de discurso que instauram seus pontos de vista a respeito da realidade criada no interior do discurso. Nesse sentido, os encapsuladores - bem como os demais processos de referenciação - precisam ser analisados levando em consideração, além da situação enunciativa imediata, as relações estabelecidas na interação. Essa análise envolve, além 
dos interlocutores, o gênero textual, aspectos contextuais e sociointeracionais e as intencionalidades articuladas à construção argumentativa do texto.

\section{Referências}

BARBEIRO, H.; RANGEL, P. Manual do jornalismo esportivo. São Paulo: Contexto, 2006.

BORREGUERO, M. Z. Naturaleza y función de los encapsuladores en los textos informativamente densos (la noticia periodística). Cadernos de Filologia Italiana, v. 13, p. 73-95, 2006.

CABRAL, A. L T; SANTOS, L W. Dêixis pessoal e verbos na construção de um objeto de discurso argumentativamente orientado. Revista Conexão Letras, v. 11, n. 15, p. 25-37, 2016.

CAVALCANTE, M. M. Referenciação: sobre coisas ditas e não-ditas. Fortaleza: Edições UFC, 2011.

; CUSTÓDIO FILHO, V.; BRITO, M.A.P. Coerência, referenciação e ensino. São Paulo: Cortez, 2014.

CONTE, M. Encapsulamento Anafórico. In: CAVALCANTE, M. et. al. (orgs.). Referenciação. São Paulo: Contexto, 2003. p. 177-190.

KOCH; Elias. Escrever e argumentar. São Paulo: Contexto, 2016.

JUBRAN, C. A. S. Inserção: um fenômeno de descontinuidade na organização tópica. In: CASTILHO, A. T. (org.). Gramática do português falado. v. III. Campinas: Editora da UNICAMP; São Paulo: FAPESP, 1992.

MONDADA, L.; DUBOIS, D. Construção dos objetos de discurso e categorização: uma abordagem dos processos de referenciação. In: CIULLA, A. et al. Referenciação. São Paulo: Contexto, 2003. p. 17-52.

MORAIS, M. M. Referenciação em campo: a construção de sentidos nas notícias esportivas. 2017. 181f. Tese (Doutorado). Rio de Janeiro: Faculdade de Letras, Universidade Federal do Rio de Janeiro, Rio de Janeiro, 2017. 
PARODI, G; BURDILES, G. Encapsulación y tipos de coherencia referencial y relacional: el pronombre ello como mecanismo encapsulador en el discurso escrito de la economía. Onomázein, n. 33, p. 107-129, 2016.

PECORARI, F. Anaphoric encapsulation and presupposition: persuasive and stereotypical uses of a cohesive strategy. Cadernos de Letras da UFF, v. 24, n. 49, p.175-195, 2014.

PINHEIRO, C. L. Integração de fatos formulativos e interacionais na construção do texto: um estudo a partir da topicalidade. 216 f. 2003. Tese (Doutorado). Universidade do Estado de São Paulo, Assis, 2003.

SANTOS, L.W.; CAVALCANTE, M. M. Referenciação: continuum anáfora-dêixis. Intersecções, Jundiaí, v. 12, n. 1, p. 224-246, maio/2014.

Recebido em 30 de agosto de 2019.

Aceite em 01 de dezembro de 2019. 